\title{
Introduction of virtual patients onto a final year anesthesia course: Hong Kong experience
}

This article was published in the following Dove Press journal:

Advances in Medical Education and Practice

23 February 201I

Number of times this article has been viewed

\author{
Joseph YC Leung' \\ Lester AH Critchley' \\ Alex LK Yung ${ }^{2}$ \\ Shekhar M Kumta ${ }^{2}$ \\ 'Department of Anaesthesia and \\ Intensive Care, ${ }^{2}$ Department \\ of Traumatology and Orthopaedics, \\ Prince of Wales Hospital, \\ The Chinese University of \\ Hong Kong, Shatin, \\ New Territories, Hong Kong
}

Correspondence: Joseph YC Leung Department of Anaesthesia and Intensive Care, Prince of Wales Hospital, The Chinese University of Hong Kong, Shatin, New Territories, Hong Kong

Tel +85226321278

Fax +85226372422

Email joseph.leung@cuhk.edu.hk

\begin{abstract}
Learning has revolutionized the way in which undergraduate medical education is delivered. One e-learning tool of note is the virtual patient (VP), a type of computer software that simulates real-life clinical scenarios, in which the learner emulates the role of health care provider to obtain the history, conduct examination, and make diagnoses and management decisions. VPs have been in use since 1993. Early designs were based on serial screen-cards of patient history, examination, investigations, diagnoses, treatment, and outcome, which the learner explored. With the development of web technology, VPs can now be accessed via the Internet and are more versatile, supporting different structural designs to suit a variety of learning objectives, and they can branch via different routes through a case. Using VPs has a number of advantages: 1) VPs improve access to learning material, 2) VPs help learners to acquire higher order cognitive skills like strategic thinking and decision making, 3) VPs provide a safe environment to practice, 4) VPs help to teach interdisciplinary care, and 5) VPs can be used instead of patients for examination. A number of well-known VP player systems are in use today: CASUS, CAMPUS, web-based Simulation of Patients, OpenLabyrinth, and vpSim. At the Chinese University of Hong Kong, we have also developed a web-based VP authoring and player system called Formative Assessment Case Studies (FACS), which is run by our Teaching and Learning Resources Centre. FACS has been integrated into Year-5 Anesthesia teaching since 2006. Three VP products have been developed: Anaesthesia FACS (six cases) that teaches preoperative assessment, Acute Pain Management FACS, and an eight-part longitudinal VP which tells the story of a patient's stay, and anesthesia care, for routine gynecological surgery. Students spend about 3 hours on each during a 2-week clinical attachment. Our VPs have been well received and have overcome problems of providing adequate clinical exposure.
\end{abstract}

Keywords: virtual patient, e-learning, anesthesia, medical education

\section{e-Learning in medical education}

Medical education is undergoing a revolutionary change. With the help of rapid improvements in computer technology and the widespread use of the Internet, e-learning has become a key teaching tool in just a short period of time. ${ }^{1}$ Learning activities like online discussions, interactive web-based exercises, tests, and assessments can now be easily set up by teachers. ${ }^{2}$ This change in the delivery of medical education is welcomed as the content of the medical curriculum has changed substantially over time with the discovery of new knowledge, but methods of delivering medical education have remained static, adhering to traditional teaching ideas.

e-Learning is not merely making information easily available in the form of word documents or slides on the Internet for students to read, thus replacing traditional course 
lecture notes and books. It encompasses a range of interactive strategies to deliver teaching material and knowledge in a better way. Furthermore, it can deliver different levels of the learning process from simple memorizing and recalling to higher cognitive functions such as clinical reasoning and creative thought. ${ }^{3}$ The traditional roles of the teacher and student are changed. The student no longer plays the passive role of listener, as he needs to participate in the learning process, while the teacher needs to learn how to assist the student in this new learning environment. Hence, the learning process is no longer purely teacher-directed, as it becomes a more learner-centered teaching experience.

In this paper, we will describe the development of one particular e-learning tool, the virtual patient (VP), and provide the example of how it has been implemented onto a 2-week undergraduate anesthesia course in Hong Kong.

\section{What is virtual patient?}

VP is an e-learning application that simulates a specific clinical situation that the teacher wants the learner to experience. It is a development from patient simulation, which used role play and manikins. Recently, a more exact definition has arisen for VPs, and the term has become synonymous with 'interactive clinical case studies'. According to the Association of American Medical Colleges, a VP is defined as a 'specific type of computer software that simulates real-life clinical scenarios, in which learners emulate the role of health care providers to obtain a history, conduct a physical exam, and make diagnostic and therapeutic decisions'. ${ }^{4}$ However, VPs can range from virtual anatomical models that facilitate the learning of human anatomy to virtual worlds where multiple users interact together, the classic example being second life, where student paramedics work together to retrieve an injured patient. ${ }^{5}$ Thus, a spectrum of virtual environments are available, and the 'interactive clinical case study' type is positioned somewhere in the middle. From now on, VP refers to the case study type.

Most VP systems use a screen-card or web page format that can be accessed easily by the student. The intention of working through a VP exercise is that the students learn as they explore the case and make clinical decisions in a virtual environment, which will enable them to apply the knowledge gained to similar real situations in the future.

A typical VP exercise will have a case history or storyline that is told through short text descriptions and pictures (clinical data), which are delivered on a succession of screencards. A key aspect of the VP exercise is its ability to promote problem solving and decision making. This is achieved by linking the cards of the VP using decision-making steps. Multiple-choice type questions (MCQs) are most commonly used, but other question types such as identifying key words can also be used. Incorrect or alternative decisions can be linked to feedback, explaining why the decision is wrong, or different routes through the case.

VPs can be provided as a software package that runs a single case on a personal computer, but more usually VP player software that manages and plays many cases from a bank is used. For the latter, a VP authoring system is also required so that new cases can be written. This software may be separate from or part of the main VP player. A server is needed to store and run the VP player that allows teachers and students to access cases from remote computer terminals usually via a network system or the Internet. A number of well-established VP players and authoring systems are in use today (Table 1).

\section{Advantages of using VPs Improved access to learning material}

Using VP technology has a number of advantages in medical and health care education. The need for access to suitable patients and teaching in the workplace is greatly reduced. This can be a problem in the busy working environment of a hospital or clinic. Previously, this had been overcome by the use of simulators, manikins, and role play, but learning still took place in the classroom. However, VP technology is not confined to the classroom. Neither is the presence of the teacher necessary. All that is needed is access to the Internet, and with rapidly developing mobile phone technology,

Table I A list of well-known virtual patient players and authoring systems available in 2010

\begin{tabular}{lll}
\hline VP system & Developed by & Web site \\
\hline CASUS & Ludwig-Maximilians University, Germany & http://www.casus.eu/ \\
CAMPUS & University of Heidelberg, Germany & http://www.campusvirtualpatients.com/ \\
Web-SP & Karolinska Institute, Sweden & http://websp.lime.ki.se/ \\
OpenLabyrinth & University of Edinburgh, Scotland' http://sourceforge.net/projects/openlabyrinth/ \\
vpSim & University of Pittsburgh, USA & http://vpsim.pitt.edu/ \\
\hline
\end{tabular}

Note: 'Currently, managed by Northern Ontario School of Medicine, Canada. Abbreviations: Web-SP, Web-based Simulation of Patients. 
this can be literally 'access it anywhere and anytime'. Thus, students can return to the learning experience whenever and for as long as they wish. Thus, VPs provide a level of access and freedom to use teaching material, which previously did not exist.

\section{Development of higher order learning skills}

VPs can be compared to computer games in which a virtual world is created and each player (or student) works through a set of tasks. By completing the tasks, the student acquires new knowledge and skills, such as strategic thinking and formulation of plans, which are considered fundamental for working as a doctor or other health professional. ${ }^{3}$ However, these skills are hard for students to acquire when curriculums are based mainly on lectures and didactic learning.

\section{Providing an environment for safe practice}

Research has shown that there are three stages to practical skills acquisition: 1) cognitive, 2) associative, and 3) autonomous. ${ }^{6}$ In the cognitive stage, the learner gains knowledge of a new skill and begins to understand how to perform the skill. In the associative stage, the learner needs to practice the skill to gain full mastery. Finally, in the autonomous stage, the skill becomes automatic and the student is able to utilize the skill and apply it to their working practice. VPs can help the student to facilitate mastery of the last two stages by allowing them to practice the skill in a virtual and safe environment. ${ }^{7}$

\section{Efficient use of teacher's time}

VPs can help teachers to use their time more efficiently. Traditional tutorial-based learning is an inefficient way of transferring knowledge, and insufficient time is spent in teaching higher level skills. ${ }^{8}$ Many teachers are doctors or health professionals with busy clinical jobs and often do not have sufficient free time to tutor students or help them if they have any specific problem. VPs can help in saving teaching time because they stimulate students to think through clinical cases independently and also facilitate group discussions, so that the student learns from other members of the group. ${ }^{2}$

\section{Teach interdisciplinary care}

VPs can also be designed to follow the patient's progress over the course of an illness or treatment. The management the patient receives may be given by several different departments within the health care system, and the VP helps to bring these different areas of care together so that the student receives a comprehensive overview of the patient's treatment and progress. VPs are particularly useful when training student nurses, which involves frequent movement between different clinical areas. ${ }^{9}$

\section{Used for assessment}

VPs not only facilitate learning, but they can also be used in assessment. VPs stripped of their formative content can be used to assess how students handle clinical situations without the need for patients. As VPs are computer-based, they can also reduce the manpower and time involved in marking oral and written examinations.

\section{Centers that use VP players}

Worldwide, there are a number of university centers that have developed VP systems, and they are situated mostly in Europe and North America (Table 1). Each VP system has its own purpose and design, being developed locally at an institutional level. ${ }^{10}$ The present situation of VP player and authoring systems has been described as 'many tribes with many designs'.

\section{The CASUS system}

The CASUS system was developed in 1993 at LudwigMaximilians University, Germany, and was the first successful VP system to be created. It uses a linear screen-card system and was designed for case-based learning. ${ }^{11}$ Cases are assembled using a classical clinical approach of history and examination, investigations, diagnosis, and treatment. The player has two modes of play: 1) classic-player that allows self-study and full exploration of the case and 2) card-player with reduced choices that directs the student through the case. The cases are created using CASUS's own authoring system. It is currently used in over 15 centers worldwide; cases have been translated into several languages, and the bank of cases currently holds over 850 .

\section{The CAMPUS system}

The CAMPUS system was developed in 1999 at the University of Heidelberg, also in Germany. Like the CASUS system, it is a linear screen-card case-based learning VP. It has an authoring system that allows the teacher to create cases directly without the need for any programming background. It has three modes of playing: 1) CAMPUS Classic which gives full access, 2) CAMPUS Card which is the simplified version, and 3) CAMPUS Testing System for examinations which is stripped of any feedback. ${ }^{12}$ 


\section{Web-SP}

Web-based Simulation of Patients (Web-SP) was developed in 2003 by Karolineska Institute in Sweden, as part of the WASP project. ${ }^{13}$ The aim was to overcome many of the technical difficulties, in developing new cases, encountered when using the older card player systems by making use of the newly emerging web-based technology. Cases remained linear in design, but it was made easier for teachers to create cases by using templates and inputting new or rearranging existing clinical data. ${ }^{14}$

\section{OpenLabyrinth}

Labyrinth was developed in early 2000 at the University of Edinburgh in Scotland. It later became open source (eg, no license fee payable for educational community uses), and its name was changed to OpenLabyrinth. Currently, it is maintained by the Northern Ontario School of Medicine in Canada and it is used by a number of centers worldwide including the e-learning Unit at St George's University of London, England. OpenLabyrinth is an application for authoring and delivering VP and other decision path activities. It is more versatile than the simple linear card player design of CACUS and CAMPUS and supports different VP designs. It can support branching VPs with different routes through the case. Authoring is done using Visual Understanding Environment software (VUE), which provides a flexible visual environment for constructing cases. ${ }^{15}$ Thus, Labyrinth is one of the new generation of versatile web-based VP player systems that are now changing the role of VPs in medical education. A good example of this is the G4 project at St George's University of London that uses branching VPs to facilitate problem-based learning in the classroom. ${ }^{16}$

\section{vpSim}

vpSim was recently developed in 2009 by the University of Pittsburgh, but has already been adopted by many medical schools across North America. It supports both linear and branched VP cases. It has a very up-to-date and user-friendly authoring system that uses a flash-based drag-and-drop visual construct interface. Currently, it supports a bank of over 170 cases from 25 user institutions. ${ }^{17}$

\section{Other centers using VPs}

This list of VP players and authoring systems is not exhaustive, and in recent years, other systems have become available, such as the McGill VP and the Maryland VP. ${ }^{18,19}$

\section{Sharing and repurposing VP cases}

Exchange of teaching material between medical schools and other health care institutions is common and has traditionally involved printed material, such as textbooks. With the advent of information technology, all sorts of electronic materials such as powerpoint presentations and videos could also be exchanged. However, exchanging VP cases has been made difficult because of the individualized nature of different VP systems, which makes the cases in their banks incompatible.

Until 2006, there was a lack of contact and communication between different centers that used VPs in medical education. In 2007, several centers in Europe came together with MedBiquitous, an organization that fosters technology standards in health care, to form Electronic Virtual Patients(eViP), a 3-year European Commission funded project. ${ }^{20} \mathrm{eViP}$ 's mission has been to promote VPs in medical education and to unify their design so that sharing between institutions of VP cases would become simple and easy. Thus, guidelines were developed for writing VP player and authoring software that would facilitate case sharing. In addition, the eViP project aimed to create a bank of 320 repurposed and enriched VPs. This bank was recently made available under a Creative Commons License. ${ }^{21}$

Repurposing involves removing unnecessary details from a case to leave the main message and important factual content. Culturally sensitive aspects of the case and features that could identify a patient, such as a religious mark or tattoos, are also removed. Clinical pictures and data from other sources that could improve the case are added. The text can also be translated into different languages. Thus, the case is now repurposed, depersonalized, possibly translated, and enriched so that it can be imported and used by any medical school worldwide with a VP player system that adheres to MedBiquitous standards.

\section{Categorizing VPs}

For VPs to be used and shared on a wide scale, it becomes necessary to be able to catalog them. Thus, a typology has been described for categorizing them based on 19 factors divided into 4 broad categories (Table 2). ${ }^{10}$

By using this system of categorization, teachers are able to easily look up VP cases that suit their needs. For example, by using the descriptors such as 'Typical study time, Educational level, and Objectives', the teacher will get a basic idea of which cases in the bank will suit their needs. In educational research, the categorization will be useful because it provides a framework for classifying different VP cases.

\section{The Hong Kong experience Formative Assessment Case Studies}

Formative Assessment Case Studies (FACS) is a VP authoring system first developed by the Department of Orthopaedics and Traumatology in 2003, following the award of a major 
Table 2 Suggested typology used for categorizing virtual patient cases

\begin{tabular}{llll}
\hline General & Educational & Instructional design & Technical \\
\hline Title & Educational level & Path type & Originating system \\
Description & Educational modes & User modality & Format \\
Language & Topics covered & Multimedia & Secondary system \\
ID & Learning objectives & Narrative use & \\
Authors & & Interactivity use & \\
Completion time & & Feedback use & \\
\hline
\end{tabular}

Modified from Huwendiek S, De leng BA, Zary N, Fischer MR, Ruiz JG, Ellaway R. Towards a typology of virtual patients. Med Teach. 2009;3I(8):743-748. ${ }^{10}$

Hong Kong Government Teaching Development Grant. It has since been refined by the Teaching and Learning Resources Centre (TLRC) of the Chinese University of Hong Kong (CUHK). The goal of creating FACS was to improve the higher order cognitive skills of students, such as critical thinking and decision making. ${ }^{22}$ Furthermore, like many e-learning tools, FACS was also intended to address the common educational issue of 'too much information to be taught by too few people in too little time', and this is especially true of clinical medicine.

FACS uses a flowchart authoring style like VUE, which facilitates the easy creation of cases (Figure 1). Unlike the VP authoring systems of CASUS and CAMPUS that use a standard clinical scenario template of history, examination, etc, to which the teacher inputs clinical data to build a case, FACS has no underlying template and the teacher must first plan the structure and content of the case, the sequence of steps through the case, and the questions, or decision steps, that control progression through the case.

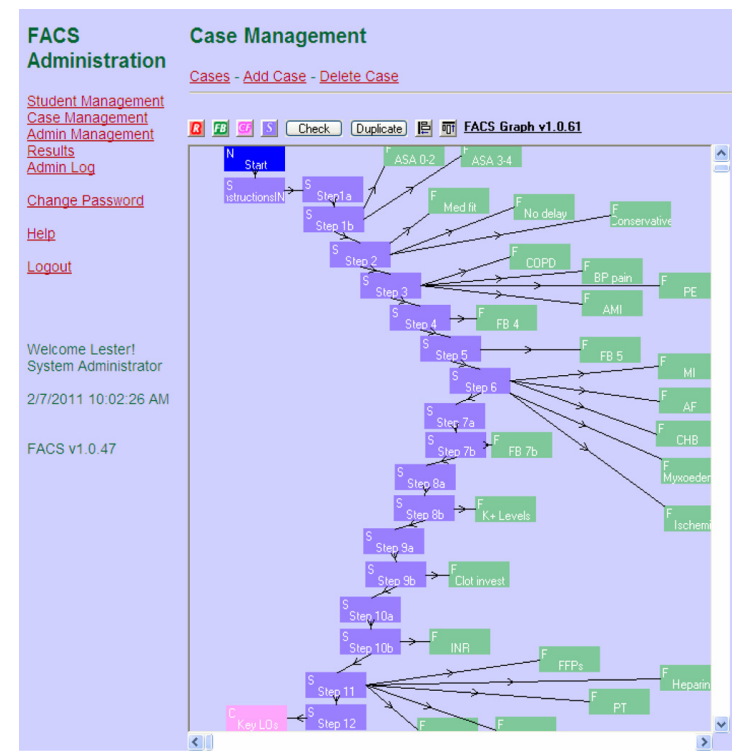

Figure I Administration page of FACS system showing flow diagram of completed case in authoring window. The design of this case is linear with consecutive violet boxes linked by arrows. Feedback is provided by the green boxes (branches). There are also start (blue) and completion (pink) of the case boxes. A red randomizer box is also available (not used). Pathways through the case can be checked and sections duplicated for future use.
The authoring system in FACS provides a number of editing windows, which allows the teacher to write directly onto FACS and add new cases to the bank (Figure 2, top). The teacher can see the content of the web page as it is written (Figure 2, bottom). However, the final look of the web page is based on the web site onto which the case is implemented. Thus, FACS cases can be easily implemented into any course web site. The web pages are linked together using the flowchart function in the authoring window (Figure 1). The authoring system provides a number of different purpose web pages, such as decision step (S) and feedback (FB). Pathways through the case can be linear (one route) or branching (multiple routes). The authoring system makes it easy to revise and reuse sections of cases at a later date.

FACS can display a variety of multimedia applications including pictures, tables, audio, and movie files. It can also link to outside web addresses such as YouTube. The authoring system enables teachers to upload multimedia files onto the web pages of the case using Browse (Figure 2). Thus, the educational value and reality of the case experienced by the student is enhanced.

The authoring system uses HyperText Markup Language (HTML) to provide text features (eg, font size, color, bold text) and layout on the web page, which may be a problem for those not familiar with HTML web page writing languages (Figure 2). However, it does allow embedding onto any website, so that the final layout of the web page is not only controlled by the FACS page template, but the teacher also has some control over the layout and design of the final web page.

FACS is web-based and is run from a central server. Students log onto the system via the Internet. The FACS administrator provides teachers with variable levels of access to author new cases and manage students' access to cases. Usage of cases is recorded and can be reviewed at a later date.

Since its introduction in 2003, FACS has been widely used in the undergraduate medical curriculum at the CUHK. It has been most popular with the final year clinical specialties, such as anesthesia, cardiology, ear, 


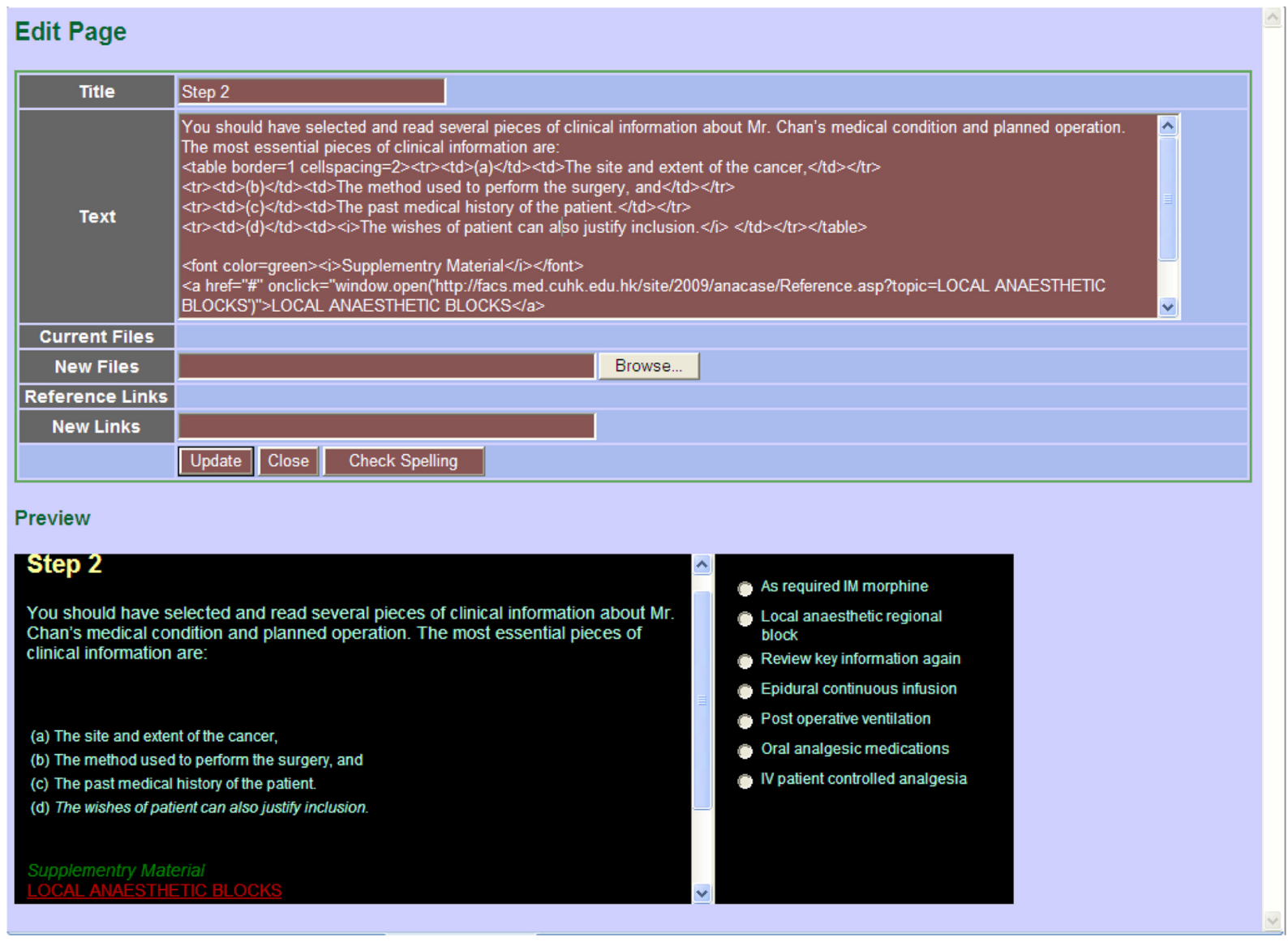

Figure 2 Typical edit page from the FACS authoring system. The editing is done on the top half of the page where teachers can type the information directly into the text box, but some HTML is also needed. Under the editing textbox is a browse button that allows authors to attach videos and other multimedia material, as well as links to useful websites. The bottom part of the page is the preview screen that shows an outline of how the page will look without an HTML template design. Note the table and different font effects. To the right is a list of multiple-choice type questions selections, which are written in a separate editing window.

nose and throat (ENT), orthopedics, and surgery. There are currently over 100 active cases in the bank. FACS has also been used by medical schools outside of Hong Kong. Currently, FACS operates from one server that manages the bank of active cases. Users of FACS have to log onto this server, which can limit the number of users at any given time. Current capacity is well over a thousand users logged on at any one time.

\section{Teaching and Learning Resource Centre}

FACS is housed and maintained at the TLRC, which is located at the Prince of Wales Hospital, the main teaching hospital of the Medical School at the CUHK and 15 minutes drive from the main university campus and preclinical school buildings. The TLRC is now under the supervision of the Office of Educational Services of the Faculty of Medicine. The main mission of the TLRC is to develop innovative teaching methods, such as FACS, and provide support for educational research within the Medical Faculty.
The center itself has a reception area with two offices, a computer server room, and a medium-sized tutorial room that can accommodate about 20 people (Figure 3 ). The tutorial room is used to host workshops and small group teaching sessions that require computer terminal access. The center is currently staffed by one part-time director, a full-time computer technologist, and two research assistants.

\section{Medical curriculum at CUHK}

The medical course at the CUHK is a 5-year systems-based undergraduate curriculum. Current enrollment is about 140 students per year. In their final year, students rotate through four 10-week surgery (two) and medicine (two) modules. Embedded in the surgery modules are short 1- or 2-week sub-speciality modules like pediatric surgery, ophthalmology, and ENT. Final year surgery students are attached to anesthesia for a 2-week module. They are divided into 16 groups of 7-10 students who attend from July to April of the next year, each academic year. 


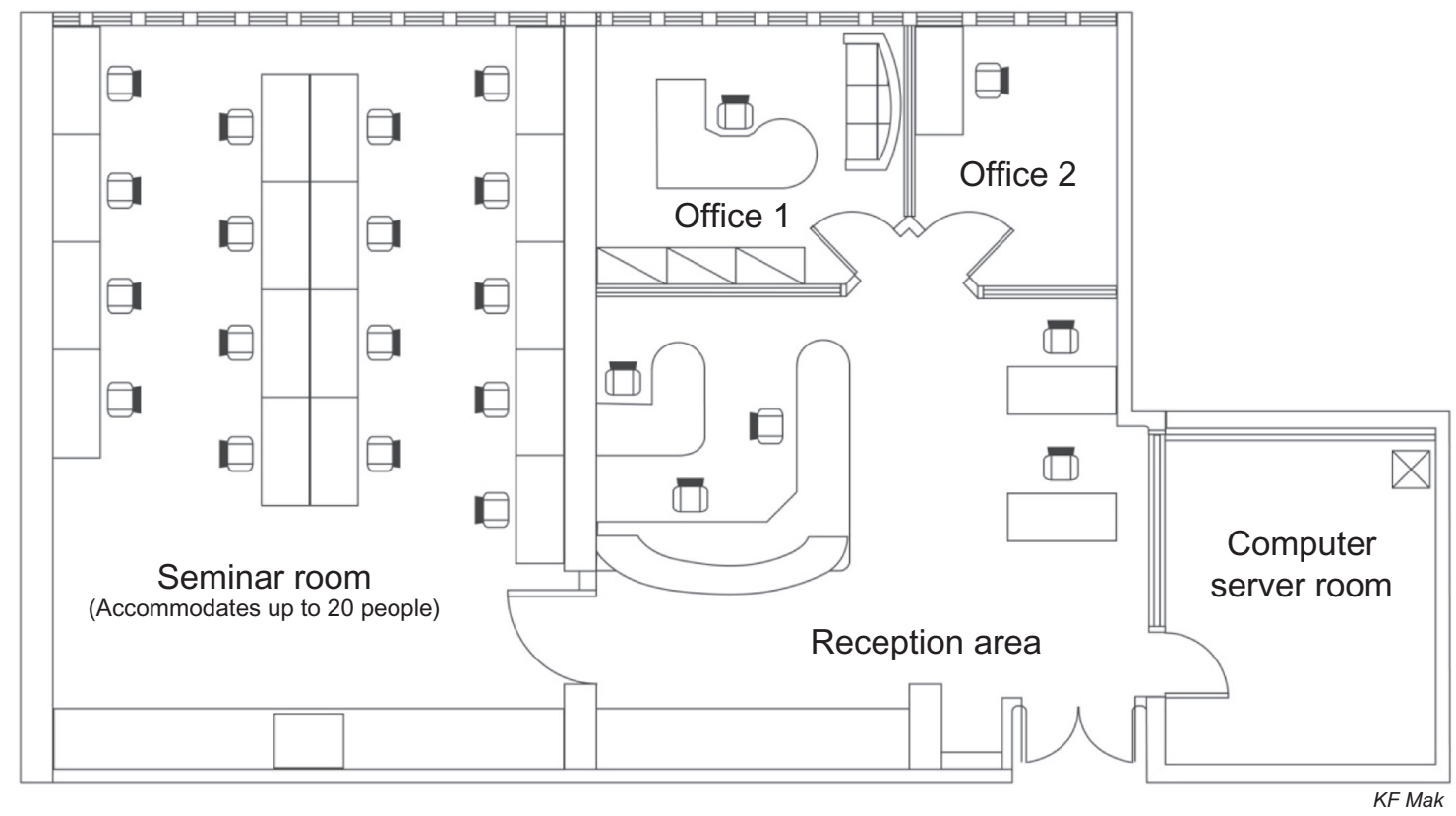

Figure 3 Floor plan of Teaching and Learning Resources Center at the Prince of Wales Hospital.

\section{Anesthesia teaching}

In previous years, Anesthesia and Intensive Care teaching at the CUHK were combined and based on morning clinical attachments and afternoon small group lectures or tutorials covering essential topics. This arrangement used teaching time inefficiently, put strains on clinical services because of lack of manpower, and caused teachers dissatisfaction because they repeated the same lecture every 4 weeks. When the medical curriculum at the CUHK was revised from a traditional specialty-based model to a system-based model in the summer of 2001, the Anesthesia and Intensive Care curriculum also changed. Intensive Care teaching became separated from Anesthesia teaching and has now been developed into a very successful 2-week acute medicine course that all 140 students attend at the same time. ${ }^{23}$ Students no longer are attached to the intensive care unit for their teaching. Intensive care colleagues find this arrangement much more rewarding as time spent on teaching is more focused. The 2-week course is also much more popular with our students and is well supported by e-learning materials. The course has also been taught by faculty members in other medical schools in the Asia-Pacific region.

In contrast, the Anesthesia curriculum was not radically changed with morning clinical attachments to the operating theatres and acute pain management rounds retained. The number of lectures and tutorial was reduced to cover a few essential topics, and the afternoons were made free for study and doing self-study course work. ${ }^{24}$
More emphasis was also put on teaching preoperative assessment and postoperative care. This was later supplemented by the development of e-learning resources and in particular VPs.

\section{Development of anesthesia e-learning resources}

We first became involved with using FACS in early 2006. At the time, FACS and the TLRC had been up and running for nearly 2 years. For many years, we had struggled with how to most effectively teach our final year students about preoperative assessment of patients admitted for surgery. Preoperative assessment is a very important part of anesthetic care and one that requires a good liaison with junior surgical residents to be successful. In other words, the junior doctor needs to have a good understanding of the requirements of the anesthetist. Ideally, preoperative assessment should be taught by attaching the student to a staff anesthetist for a period of 1-2 weeks, so that the student sees patients being assessed and given anesthesia by the same person first hand. However, in a busy teaching hospital where time is limited, students often outnumber available staff and many staff have portfolio jobs where they do only one or two theatre sessions per week, so that such scheduling of student attachments is not always possible. At the Prince of Wales Hospital preoperative ward round attachments are arranged in a very impromptu manner with the student contacting the list anesthetist. Thus, one solution is to use VPs. Therefore, we wrote six FACS cases 
to address key preoperative issues and introduced them into the anesthesia curriculum in the summer of $2006 .{ }^{24}$

Following the successful introduction of the six FACS cases onto our course in the summer of 2006, a Teaching Development Grant was successfully applied for to develop a longitudinal VP that would describe the sequence of events and perioperative care of a patient being admitted to the hospital for a routine surgical procedure. ${ }^{25}$ The project was inspired by the VPs developed by Edinburgh University Medical School that depicted $a$ ) the course of a pregnancy (Hannah), b) the progress of chronic lung disease over several years (George), and $c$ ) alcohol-related problems in society (The Wedding Party) (unpublished teaching development). Students attending our 2-week Anesthesia course witness only 'snap-shots' of patient care, and by developing a perioperative VP, our intention was to fill in the missing gaps for the students and provide them with a complete picture of a patient's stay in hospital, from an anesthetic view point, from the day of admission to discharge. Work on the project started in the spring of 2007 with the completed VP being launched a year later in the summer of 2008. The design and purpose of our perioperative VP was quite different from the interactive case study VPs so far described.

Feedback from our students supported the need for more FACS cases on the course and in particular to supplement our teaching of acute pain management, which consisted of one morning attached to the acute pain management team ward round and a 1-hour tutorial. Patients returning from major surgery often receive intravenous patient controlled analgesia (IV PCA) morphine or continuous infusion epidural analgesia. These pain management modalities are potentially harmful if they malfunction. The junior doctor on the postsurgery ward is often the first medical person called to deal with any IV PCA pump or epidural infusion-related problems. Therefore, they should have some knowledge of how these advanced treatments for postoperative pain relief work and the potential complications. Therefore, in the spring of 2009, we wrote further three FACS cases to cover the key points of using IV PCA morphine and epidural infusions on the postsurgical ward. These acute pain management FACS were introduced onto our course in the summer of 2009.

\section{Detailed descriptions of these VPs}

\section{Preoperative FACS cases}

Six FACS cases were written to cover routine anesthetic assessment and the main issues of managing patients with common medical conditions, such as chronic lung disease, heart disease, and diabetes (Table 3).

The cases were supplemented by providing links to additional supplementary material on essential topics (Figure 4).

Each web page of the FACS had a common design with main text providing information about the case supplemented by pictures and tables showing clinical data. At the bottom of the page was a question, if a decision step, with the multiple-choice answers displayed in the upper-right corner. A running performance score for FACS was also provided (Figure 5).

Students were shown how to use the FACS site, and additional study time was allocated. Each student used their

Table 3 Outline and content of the six Anesthesia FACS cases

\begin{tabular}{|c|c|c|c|c|c|}
\hline & Title & Web pages & Decision steps & Case scenario & Content \\
\hline I & $\begin{array}{l}\text { Preoperative } \\
\text { assessment }\end{array}$ & 41 & 12 & $\begin{array}{l}\text { A } 43 \text {-year-old man admitted for } \\
\text { retinal detachment surgery }\end{array}$ & $\begin{array}{l}\text { The main steps involved in routine } \\
\text { anesthetic assessment and planning }\end{array}$ \\
\hline 2 & Laboratory data & 44 & 11 & $\begin{array}{l}\text { An elderly woman has a traumatic } \\
\text { hip fracture }\end{array}$ & $\begin{array}{l}\text { Abnormal preoperative laboratory } \\
\text { investigation results and how they should } \\
\text { be managed }\end{array}$ \\
\hline 3 & Spinal anesthesia & 49 & 12 & $\begin{array}{l}\text { An elderly man with hypertension } \\
\text { for transurethral resection of the } \\
\text { prostate under spinal anesthesia }\end{array}$ & $\begin{array}{l}\text { Assessment of a patient requiring spinal } \\
\text { anesthesia and preoperative management } \\
\text { of hypertension }\end{array}$ \\
\hline 4 & Diabetes & 32 & 9 & $\begin{array}{l}\text { A 49-year-old diabetic man } \\
\text { is admitted with a back abscess }\end{array}$ & $\begin{array}{l}\text { Perioperative care of the diabetic patient, } \\
\text { planning of cases, and the ASA scoring } \\
\text { system }\end{array}$ \\
\hline 5 & Chronic lung disease & 46 & 13 & $\begin{array}{l}\text { An elderly man with chronic bronchitis } \\
\text { for a total abdominal gastrectomy }\end{array}$ & $\begin{array}{l}\text { Assessment and risks in a patient with } \\
\text { chronic lung disease having major surgery }\end{array}$ \\
\hline 6 & Heart disease & 36 & 10 & $\begin{array}{l}\text { A } 25 \text {-year-old woman is admitted } \\
\text { with an ectopic pregnancy }\end{array}$ & $\begin{array}{l}\text { Fluid resuscitation in a patient with an } \\
\text { acute abdomen and preoperative evaluation } \\
\text { of a heart murmur }\end{array}$ \\
\hline
\end{tabular}

From Critchley LA, Kumta SM, Ware J, Wong JW. Web-based formative assessment case studies: role in a final year medicine two-week anaesthesia course. Anaesth Intensive Care. 2009;37(4):637-645. ${ }^{24}$

Abbreviation: ASA, American Society of Anesthesiologists. 


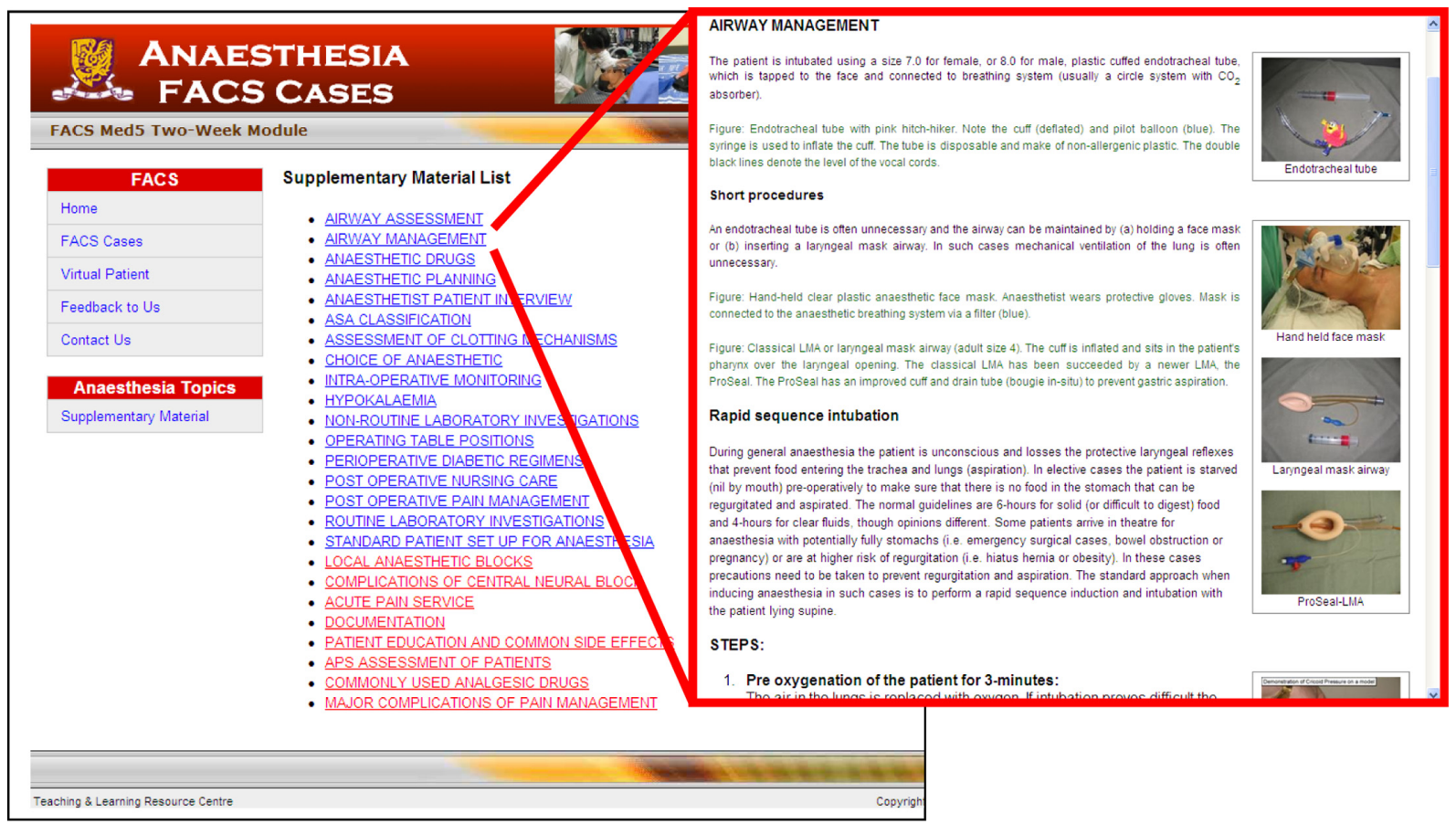

Figure 4 List of supplementary materials that students can read as they are working on the FACS cases. The ones in blue are for the preoperative cases and the ones in red are for the pain management cases. Insert (right) shows typical supplementary page.

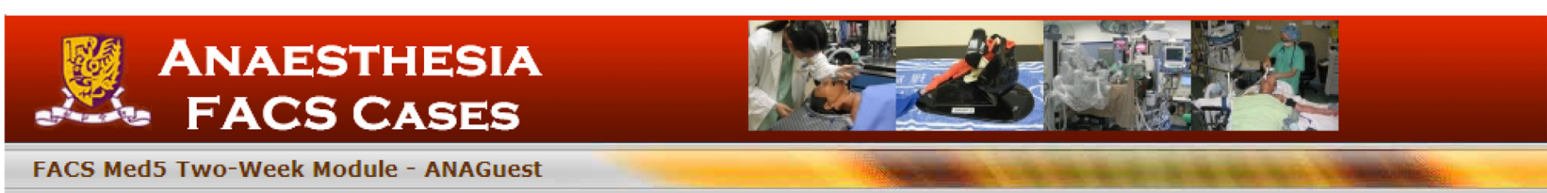

FACS Med5 Two-Week Module - ANAGuest

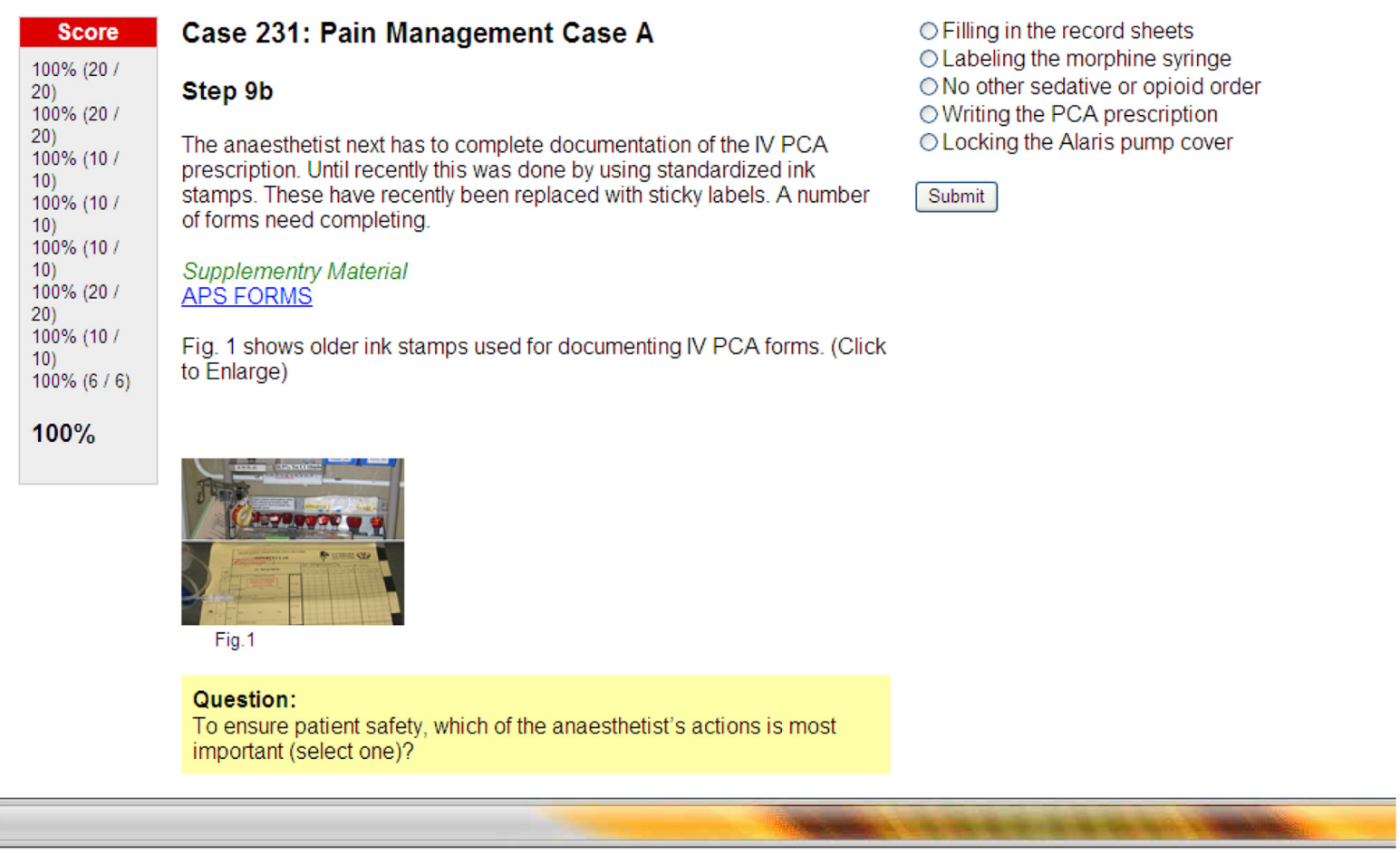

Figure 5 A typical web page from FACS. Note the common web format template for the FACS cases. The main text contents are in the middle of the page with a question (highlighted in yellow) at the bottom of the page. Also included are clinical pictures and links to other web pages. Answer choices are on the right hand side with a running score on the left. 
Table 4 Outline and contents of the perioperative VP

\begin{tabular}{|c|c|c|c|c|c|}
\hline Chapter & Title & Web pages & Pictures & Questions & Content \\
\hline I & The pre-admission clinic & 30 & 24 & 5 & $\begin{array}{l}\text { Guides the students through a typical preoperative assessment } \\
\text { of a patient who has several common medical conditions }\end{array}$ \\
\hline $2 \mathrm{a}$ & Admission to the ward & 23 & 18 & 3 & Introduces students to anesthesic preoperative investigations \\
\hline $2 b$ & Examination of Shirley & 15 & 19 & 2 & $\begin{array}{l}\text { Importance of consultation, planning, and preparation of } \\
\text { anesthesia is shown }\end{array}$ \\
\hline $3 a$ & Preparing the theatre & 24 & 40 & 4 & $\begin{array}{l}\text { Operating theatre is shown here along with the importance } \\
\text { of patient safety }\end{array}$ \\
\hline $3 b$ & Starting the operation & 26 & 41 & 6 & Issues regarding the induction of anesthesia are introduced \\
\hline 4 & Events in the theatre & 25 & 42 & 5 & Anesthetist's role and duties during the surgery \\
\hline 5 & The recovery room & 21 & 20 & 4 & Reverse the anesthetic and issues with complications \\
\hline 6 & Pain management & 21 & 35 & 2 & $\begin{array}{l}\text { Introduction of the Acute Pain Service, PCA pumps along } \\
\text { with drug used }\end{array}$ \\
\hline
\end{tabular}

Abbreviations: PCA, patient controlled analgesia; VP, virtual patient.

ID number and password to log on to the site which allowed us to monitor usage. They were advised to complete all the six cases but it was not compulsory. Student usage and opinion of FACS during the first year of use was collected. ${ }^{24}$

\section{Perioperative virtual patient}

The storyline of this perioperative VP involves Shirley, a middle-aged woman, who is referred to the hospital with uterine fibroids and requires an abdominal hysterectomy. She has diabetes, anemia, hypertension, and a history of recent deep vein thrombosis. The VP follows her hospital admission (Table 4) and focuses on the anesthetic issues at each stage. The VP is divided into eight sections with six chapters, two of which are subdivided into two parts. The VP is enriched by detailed descriptions of many aspects of anesthetic care. ${ }^{25}$

Whereas, a typical FACS case consists of 10-15 decision steps and 30-40 web pages, the perioperative VP had well over a hundred consecutive web pages and used a different textbased assessment system not supported by the FACS player.
Therefore, new VP player software was written to support its delivery. In structure, it was a simple linear series of web pages without any branching to feedback pages. Navigation was based on simple back, next, and logout commands at the foot of each page, rather than correctly answering questions as in FACS. However, it was accessed and delivered via our main FACS server home page. Figure 6 shows the main menu page and a sample page from the VP exercise.

The user is tested on their understanding of the patient's management throughout the VP by a series of self-assessment pages, which appear throughout the storyline as question and answer web pages. They are invited to type in an answer, and their text response is recorded. A subsequent web page displays an ideal answer with suggested mark allocation and the typed response from the previous web page. Then the user is invited to self-score their performance, which goes toward a final mark on completing the exercise. Self-scoring systems overcome the problem of how to mark free text answers without teacher input (Figure 7).
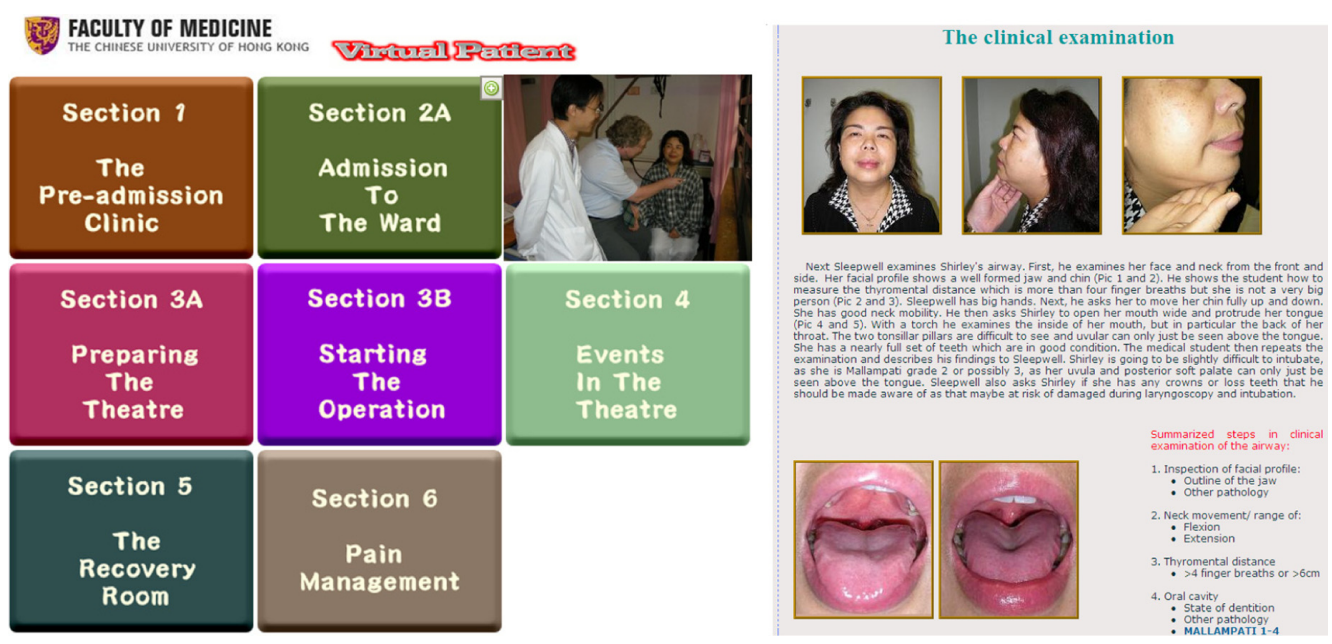

Figure 6 Index page (left) and typical web page (right) from the perioperative virtual patient. 


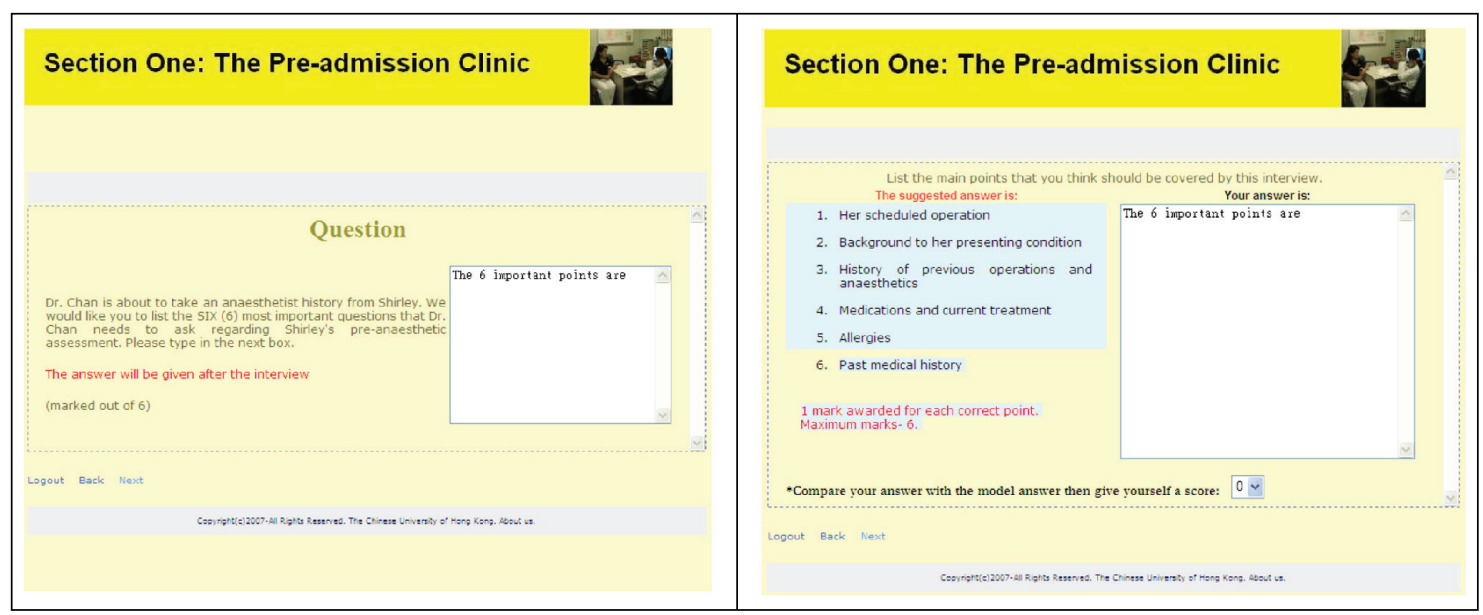

Figure 7 Question (left) and answer (right) pages of the perioperative virtual patient (VP). The white text box enables the user to input their answers to the questions (left). The answer page displays a model answer (in light-blue text box) and the user's response (in white text box on the far right). A suggested making system is provided with a scroll menu (bottom right) for user to self-score their answer.

\section{Acute pain management FACS}

The three acute pain management FACS cases used the same web page formats as preoperative FACS cases. Topics covered were 1) setting up an IV PCA morphine pump in the operating theatre, 2) providing adequate pain relief on the postsurgical ward, and 3) setting up and running an epidural continuous infusion (Table 5). As evident by comparing Tables 3 and 5, our pain management cases were longer and contained more information than the previous anesthesia cases.

We also use these three FACS cases to study the effects of e-learning and VPs on learning by looking at whether their introduction onto our course affected examination results. Exposure to pain management FACS improved student performance in three separate written and MCQ examinations (unpublished work).

\section{Usage and student opinion}

We evaluated the usage of Anesthesia FACS and the storyline VP from login data recorded by the TLRC server. Most students logged on to each site for over 3 hours during their 2-week attachment. ${ }^{24}$
For over a decade, the CUHK has evaluated its teachers and teaching by the use of a six-point Likert disagree-agree student-teacher questionnaire. A number of common question items evaluating teaching quality (Table 6) and course organization have been developed, which have been standardized for courses throughout the university using results from several thousand classes. We used four of these items to regularly assess our teaching performance over a 5 -year period (Table 6). Prior to the introduction of FACS and the storyline VP onto our anesthesia module, the course scored just above the 50th percentile for teaching effectiveness and satisfaction. Following the introduction of our interactive VPs, the questionnaire scores were improved to above the 75 th percentile, or top $25 \%$ of CUHK courses, providing evidence of an improvement in our teaching process (Table 6).

Other questionnaire items scored FACS as a learning tool (5.2/6.0) as highly as clinical skills practice (5.2/6.0) (university median: 5.0/6.0), whereas the storyline VP scored less well (4.6/6.0). Most aspects of the course, such as acute pain management, emergency anesthesia, and obstetric anesthesia teaching, scored 4.8-5.0/6.0, while the written case reports

Table 5 Outline and content of the pain management FACS

\begin{tabular}{|c|c|c|c|c|}
\hline Title & Web pages & Decision steps & Case scenario & Content \\
\hline Case A & 79 & 14 & Mr Chan is scheduled for abdominal surgery & $\begin{array}{l}\text { Introduces the students to acute pain service and } \\
\text { common IV PCA pumps along with the drugs used }\end{array}$ \\
\hline Case B & 76 & 16 & Mr Tong arrives in the ward after surgery & $\begin{array}{l}\text { PCA pump setting is understood and when to wean } \\
\text { from IV PCA and start oral analgesics }\end{array}$ \\
\hline Case C & 66 & 12 & Mrs Dong needs an abdominal operation & $\begin{array}{l}\text { The role of the acute pain service and the daily } \\
\text { assessment of patients receiving epidural analgesia } \\
\text { are taught. The dangers of overdose and prevention } \\
\text { are also mentioned }\end{array}$ \\
\hline
\end{tabular}


Table 6 Mean student-teacher evaluation scores (graded I-6) collected over a 5-year period

\begin{tabular}{|c|c|c|c|c|c|c|c|}
\hline Year of study & $2005 / 2006$ & $2006 / 2007$ & $2007 / 2008$ & 2008/2009 & $2009 / 2010$ & Other courses & \\
\hline Students in each year $(n)$ & $|5|$ & 152 & 139 & 118 & 114 & 50th percentile & 75th percentile \\
\hline Intervention: & Before & FACS & FACS-VP & FACS-VP & FACS-VP & & \\
\hline \multicolumn{8}{|l|}{ Questions: } \\
\hline $\begin{array}{l}\text { I gained a good understanding of } \\
\text { concepts/principles }\end{array}$ & 4.66 & 4.73 & 4.89 & 4.96 & 4.89 & 4.62 & 4.90 \\
\hline I deepened my interest in the subject & 4.70 & 4.80 & 4.84 & 4.93 & 4.86 & 4.50 & 4.84 \\
\hline Overall satisfaction with course & 4.76 & 4.91 & 5.09 & 5.01 & 5.00 & 4.63 & 4.79 \\
\hline Overall satisfaction with teachers & 4.91 & 5.04 & 5.18 & 5.04 & 5.08 & 4.81 & 4.95 \\
\hline
\end{tabular}

Notes: Preoperative FACS was introduced onto the course in 2006/07 and the perioperative VP in 2007/2008. Data are from four general questions that are used by the CUHK to evaluate every course. For comparison, 50th and 75th percentile evaluation scores for the whole university are provided.

Abbreviations: VP, virtual patient; CUHK, Chinese University of Hong Kong; FACS, Formative Assessment Case Studies.

received the lowest score (4.4/6.0). Positive written comments by our students included 'FACS is very useful and informative' with calls for more FACS cases. Negative comments were that the storyline VP was too detailed and took a long time to complete.

We also e-surveyed 75 students in year 2008-2009 using a 5-point Likert scale and asked their opinion of using both e-learning sites, FACS, and storyline VP. ${ }^{26}$ Most students preferred FACS over the storyline VP (3.4-3.8/5.0). In free text comments, our students liked the easy access to information $(8 / 48)$, interactive nature (8/48), and real-life clinical scenarios (7/48) of FACS, and the realistic experience (12/58) and informative nature (10/58) of the storyline VP. They disliked the use of a long and detailed narrative in the storyline VP (29/58). ${ }^{26}$ However, the storyline VP did provide something different, and most students agreed that it gave a realistic experience of meeting and providing anesthesia care to a patient undergoing surgery, which was a very positive point, because this supported the aim of the storyline VP - to give students a realistic experience of an area which the anesthesia module was previously unable to fully provide. We are yet to finish collecting and analyzing similar data evaluating the introduction of the pain management FACS.

\section{Reflections and future issues}

We have now been using VPs on our Anesthesia course for over 4 years. The students in general like them and benefit from their use. However, we have to fit in with a busy and demanding final academic year, and usage of our VPs falls off around the times of important surgical examinations. ${ }^{24}$ The interactive nature of Anesthesia FACS is more popular among our students than the storytelling nature of the storyline VP, and one has to question whether its style does not suite our mainly 'English as a second language' Hong Kong students. The primary the storyline VP, which contains many pictures illustrating equipment used in the operating theatres and postsurgical wards, soon becomes out of date and its content needs regular updating. For example, our hospital has recently 1) replaced all our IV PCA pumps, 2) changed and withdrawn some medications like Dologesic ${ }^{\circledR}$ that was frequently used for postoperative pain management, 3) moved into a new hospital building and operating complex, and 4) introduced new paperwork to improve patient safety, all of which are changes that alter the work of surgical house officers in our hospital. Therefore, our storyline VP needs revising to make it more appealing to students and up to date.

\section{Conclusions}

e-Learning will continue to grow and have an important role in medical education. In Hong Kong and more specifically the CUHK, FACS has been central in creating VPs for undergraduate medical teaching. While FACS had been a success since its launch, different ideas of how VPs should be used like our Anesthesia storyline VP also arise. Thus, teachers need to be able to evaluate the pros and cons of each type of VP within the curriculum. One of the biggest challenges now facing e-learning is the rapid development of mobile phone technology, and this will place increasing demands on the usage of systems like FACS.

\section{Disclosure}

The authors report no conflicts of interest in this work.

\section{References}

1. Taekman JM, Shelley K. Virtual environments in healthcare: immersion, disruption, and flow. Int Anesthesiol Clin. 2010;48(3):101-121.

2. Ellaway R, Masters K. AMEE Guide 32: e-Learning in Medical Education. Association for Medical Education in Europe (AMEE); 2008.

3. Federation of American Scientists. Harnessing the Power of Video Games for Learning. Available from: http://fas.org/gamesummit/Resources/ Summit\%20on\%20Educational\%20Games.pdf. Accessed October 1, 2010 . 
4. Association of American Medical Colleges. Effective Use of Educational Technology in Medical Education: Summary Report of the 2006 AAMC Colloquium on Educational Technology. Washington (DC): AAMC; 2007. p. 7.

5. Conradi E, Kavia S, Woodham L, Poulton T, Rice A. Virtual training in virtual world. Med Educ. 2010;44 Suppl 4:8-9.

6. Fitts PM, Posner MI. Human Performance. Belmont (CA): Brooks/ Cole; 1967.

7. Chuang YH, Cheng HR, Yang YS, Fang MC, Chen YP. The effects of a web-based supplementary program for facilitating nursing students' basic nursing skills. Comput Inform Nurs. 2010;28(5):305-310.

8. Shen J, Joynt GM, Critchley LA, Tan IK, Lee A. Survey of current status of intensive care teaching in English-speaking medical schools. Crit Care Med. 2003;31(1):293-298.

9. Halabisky B, Humbert J, Stodel EJ, et al. eLearning, knowledge brokering, and nursing: strengthening collaborative practice in long-term care. Comput Inform Nurs. 2010;28(5):264-273.

10. Huwendiek S, De leng BA, Zary N, Fischer MR, Ruiz JG, Ellaway R. Towards a typology of virtual patients. Med Teach. 2009;31(8): 743-748.

11. Fischer MR. CASUS - An authoring and learning tool supporting diagnostic reasoning. Zeitschrift fur Hochschuldidaktik. 2000;1:87-98.

12. CAMPUS-Software. Centre for Virtual Patients Web Site. Available from: http://www.medizinische-fakultaet-hd.uni-heidelberg.de/ Centre-for-Virtual-Patients.109881.0.html?\&L=en. Updated 2009. Accessed October 10, 2010.

13. Zary N, Fors UG. WASP - a generic web-based, interactive, patient simulation system. Stud Health Technol Inform. 2003;95:756-761.

14. Web-SP. Virtual Patients Lab. Available from: http://websp.lime.ki.se. Updated September 15, 2010. Accessed October 10, 2010.

15. Visual Understanding Environment. Tufts University. Available from: http://vue.tufts.edu/. Updated July 1, 2010. Accessed November 20, 2010.
16. Generation 4. e-Learning Unit, SGUL. Available from: http://www.etu. sgul.ac.uk/g4/. Updated November 21, 2010. Accessed November 22, 2010.

17. $v p$-Sim. Lab for Educational Technology. Available from: http://vpsim. pitt.edu/. Updated 2010. Accessed October 10, 2010.

18. DiagnosisX. MMi. Available from: http://cases.mmi.mcgill.ca/. Updated 2009. Accessed October 10, 2010.

19. McShane M, Nirenburg S, Beale S, Jarrell B, Fantry G. Knowledge-based modeling and simulation of diseases with highly differentiated clinical manifestations. Proceedings of the 11th Conference on Artificial Intelligence in Medicine (AIME 07); 2007 Jul 7-11; Amsterdam, The Netherlands. Abstract 34.

20. In About eViP. eViP Electronic Virtual Patients. Available from: http:// www.virtualpatients.eu/about/about-evip/ Electronic Virtual Patients. Updated 2010. Accessed October 10, 2010.

21. Ellaway R. OpenLabyrinth. Available from: http://sourceforge.net/ projects/openlabyrinth/. Updated 2010. Accessed October 10, 2010.

22. Kumta SM, Tsang PL, Hung LK, Cheng JCY. Fostering critical thinking skills through a web-based tutorial programme for final year medical students - a randomized controlled study. J Educ Multimed Hypermed. 2003;12(3):267-273.

23. Gruber PC, Gomersall CD, Joynt GM, Shields FM, Chu MC, Derrick JL; Very BASIC Development Group. Teaching acute care: a course for undergraduates. Resuscitation. 2007;74(1):142-149.

24. Critchley LA, Kumta SM, Ware J, Wong JW. Web-based formative assessment case studies: role in a final year medicine two-week anaesthesia course. Anaesth Intensive Care. 2009;37(4):637-645.

25. Critchley LA, Wong JW, Leung JY. Virtual patients and undergraduate anaesthesia teaching. Med Educ. 2008;42(10):1120-1121.

26. Leung JY, Critchley LA, Yung AL, Kumta SM. A comparison of two types of virtual patient used to teach perioperative care to final year medical students: interactive case studies versus story line scenario. Med Educ. 2010;44 Suppl 4:1.
Advances in Medical Education and Practice

\section{Publish your work in this journal}

Advances in Medical Education and Practice is an international, peerreviewed, open access journal that aims to present and publish research on Medical Education covering medical, dental, nursing and allied healthcare professional education. The journal covers undergraduate education, postgraduate training and continuing medical education

\section{Dovepress}

including emerging trends and innovative models linking education, research, and healthcare services. The manuscript management system is completely online and includes a very quick and fair peer-review system. Visit http://www.dovepress.com/testimonials.php to read real quotes from published authors. 